Journal of Patient-Centered

$1-28-2019$

\title{
Patient Perceptions of Planned Organ Removal During Hysterectomy
}

\author{
Zeinab Kassem \\ Chad M. Coleman \\ Andrew S. Bossick \\ Wan-Ting Su \\ Roopina Sangha \\ Ganesa Wegienka
}

Follow this and additional works at: https://aah.org/jpcrr

Part of the Clinical Epidemiology Commons, Medical Anatomy Commons, Obstetrics and Gynecology Commons, Public Health Education and Promotion Commons, Surgery Commons, and the Women's Health Commons

\section{Recommended Citation}

Kassem Z, Coleman CM, Bossick AS, Su WT, Sangha R, Wegienka G. Patient perceptions of planned organ removal during hysterectomy. J Patient Cent Res Rev. 2019;6:28-35. doi: 10.17294/2330-0698.1658

Published quarterly by Midwest-based health system Advocate Aurora Health and indexed in PubMed Central, the Journal of Patient-Centered Research and Reviews (JPCRR) is an open access, peer-reviewed medical journal focused on disseminating scholarly works devoted to improving patient-centered care practices, health outcomes, and the patient experience. 


\title{
Patient Perceptions of Planned Organ Removal During Hysterectomy
}

\author{
Zeinab Kassem, MD, ${ }^{1}$ Chad M. Coleman, MPH, ${ }^{1}$ Andrew S. Bossick, MPH, ${ }^{1}$ Wan-Ting Su, PhD, ${ }^{1}$ \\ Roopina Sangha, MD, MPH, ${ }^{2}$ Ganesa Wegienka, $\mathrm{PhD}^{1}$ \\ ${ }^{1}$ Department of Public Health Sciences, Henry Ford Health System, Detroit, MI; '2Department of Obstetrics and \\ Gynecology, Henry Ford Hospital, Detroit, MI
}
Purpose $\quad$ Previous reports indicate many women may not have a firm grasp on likely outcomes of different hysterectomy procedures. This study aimed to assess women's self-reported expectations of how they think their anatomy will change after hysterectomy.
Methods Women scheduled for hysterectomy at a tertiary care hospital, for non-oncological reasons, reported their planned procedure type and the organs they understood would be removed 2 weeks prior to surgery. Patient reports and electronic medical records were reviewed, and kappa statistics (K) were calculated to assess agreement for all women and within subgroups.

Results Most of the 456 study participants (mean age: $48.02 \pm 8.29$ years) were either white/Caucasian $(n=238,52.2 \%)$ or African American ( $n=196,43.0 \%)$. Among the 145 participants who reported a partial hysterectomy, $130(89.7 \%)$ women indicated that their uterus would be removed and $52(35.9 \%)$ reported that their cervix would be removed. Of those whose response was total hysterectomy $(n=228), 208$ $(91.2 \%)$ participants reported their uterus would be removed and $143(62.7 \%)$ reported their cervix would be removed. Among 144 women reporting a planned partial hysterectomy, only $15(10.4 \%, \mathrm{k}=0.05)$ had a partial hysterectomy recorded in the electronic medical record. Among the 228 women who reported a planned total hysterectomy, $6.1 \%(\mathrm{k}=0.05)$ had a different procedure. While 125 participants reported planned ovary removal, only $93(74.4 \%, \mathrm{k}=0.55)$ had an oophorectomy. Similarly, 290 participants reported planned fallopian tube removal, with $276(95.2 \%, \mathrm{k}=0.06)$ having a salpingectomy.

Conclusions A considerable proportion of women undergoing hysterectomy do not accurately report the organs that are planned be removed during their hysterectomy. This work demonstrates the need to improve patient understanding of their clinical care and its implications. (J Patient Cent Res Rev. 2019;6:28-35.)

Keywords hysterectomy; patient education; patient expectations; gynecology; patient-centered outcomes

$\mathrm{S}$ ince it was first performed in $1843,{ }^{1}$ hysterectomy has become the most common nonobstetrical surgery for women in the United States. ${ }^{2,3}$ Hysterectomy can involve removal of only the uterus (partial hysterectomy), removal of the uterus and the cervix (total hysterectomy), and removal of the uterus, cervix, and upper one-third to upper one-half of the vagina (radical hysterectomy). Hysterectomy may be

Correspondence: Zeinab Kassem, MD,

Department of Public Health Sciences, 1 Ford Place, 5C, Detroit, MI 48202 (kzeinab10@gmail.com) paired with additional surgeries, including removal of one or both ovaries (oophorectomy) or removal of the fallopian tubes (salpingectomy). The most common indication for hysterectomy is uterine fibroids, ${ }^{4}$ and most women report satisfaction and improvement in functioning after surgery. ${ }^{5-7}$ Due to the high frequency of hysterectomy, clinical research related to this surgery remains important.

Focus groups with 24 hysterectomy patients from an integrated health system based in Detroit, Michigan, indicated that some women were not able to report all procedures performed as part of their hysterectomy. ${ }^{8}$ More specifically, multiple women did not know if 
they retained their ovaries, fallopian tubes, or cervix after their hysterectomy. Some women reported having a "total hysterectomy" and assumed that meant they no longer had ovaries or fallopian tubes. If women do not know whether they have these organs, they may not be receiving appropriate health care such as counseling regarding hormone replacement therapy and certain recommended screenings (eg, the Papanicolaou "Pap" test for cervical cancer screening). Women who cannot report whether they have ovaries may not be able to appropriately discuss their cardiovascular disease or cancer risk with health care providers.

The frequency of this lack of understanding is not well known. As this can have important health implications on the individuals involved, it is important to investigate in a systematic manner whether the results of the focus group study are isolated findings or whether deficiencies in understanding of hysterectomy is a more common problem that health care professionals should address. The aim of this work is to assess the accuracy with which patients report their expected anatomical changes from their hysterectomy and whether they varied by procedure indication or demographic characteristics.

\section{METHODS}

\section{Study Population}

Women scheduled for hysterectomy at Henry Ford Health System (Detroit, MI) who were at least 18 years of age and not undergoing surgery for suspected cancer or having a concomitant urogynecology procedure were invited to participate in a longitudinal cohort study to examine postsurgery regret. Eligible women were sent an introduction letter explaining the study and were contacted by telephone to complete a baseline interview in the 2 weeks before the patient's scheduled surgery. Not all women who enrolled in the study had their planned surgery due to personal or clinical reasons. All women who completed the baseline questionnaires were included in the analyses of planned procedures and expected organ/tissue removal; however, only those who had a hysterectomy were included in analyses comparing self-report of surgical plans with actual surgical procedure performed.

The study protocols were approved by the local institutional review board, and consent was provided by all participants. The study was funded through the Agency for Healthcare Research and Quality of the U.S. Department of Health and Human Services.

\section{Data Collection}

In the baseline questionnaire, women were asked which hysterectomy procedure they planned to have: total, partial, radical, or “don't know." They were then asked to select from the following list every organ/tissue they expected to be removed: ovary/ovaries, fallopian tube(s), partial/complete uterus, and partial/complete cervix. Answer options were presented in this manner to assess each woman's understanding of clinical terminology. Women were asked to report their race and marital status (married or living as married vs not married or living as married). At 6 months posthysterectomy, the electronic medical record (EMR) of each participant was reviewed for surgical details, including surgical approach and organs/tissues removed as well as insurance type and indications for surgery, to assess accuracy of reporting within subgroups.

\section{Statistical Analyses}

Contingency tables, including frequencies and percentages, were created for the following pairs of variables: 1) the expected surgeries (partial/total hysterectomy) and the expected organs for removal; 2) the expected surgeries and the surgeries documented in the EMR; and 3) the EMR-documented surgeries and the reports of expected organ removal. Kappa coefficients with $95 \%$ CI were calculated to test the level of agreement between the two binary outcome variables..$^{9,10}$

\section{RESULTS}

Table 1 provides summary statistics for study participants. Mean age of the 456 participants was $48.0 \pm 8.3$ years, and most were either white/Caucasian $(n=238,52.2 \%)$ or African American ( $n=196,43 \%)$. More than half the women were married or living as married and were employed full-time. Most of the participants (71.4\%) had private insurance, and $27.1 \%$ had Medicaid and/ or Medicare. Of the 456 women who enrolled, 452 (99.1\%) women did undergo hysterectomy.

\section{Expected Surgery vs Organ Removal}

Among the 145 participants who reported that they were scheduled for a partial hysterectomy, 130 (89.7\%) 
Table 1. Descriptive Information About Participants Included in Analysis ( $\mathrm{N}=456)$

\begin{tabular}{lc}
\hline Characteristic & $\mathbf{n ~ ( \% )}$ \\
\hline Race & \\
African American & $196(43.0 \%)$ \\
White/Caucasian & $238(52.2 \%)$ \\
Others & $22(4.8 \%)$ \\
Current marital status & \\
Divorced & $80(17.5 \%)$ \\
Married/Living as married & $244(53.5 \%)$ \\
Never married & $105(23.0 \%)$ \\
Separated & $10(2.2 \%)$ \\
Widowed & $17(3.7 \%)$ \\
Employment status & \\
Employed full-time & $254(55.7 \%)$ \\
Employed part-time & $46(10.1 \%)$ \\
Self-employed & $11(2.4 \%)$ \\
Student and not working for pay & $5(1.1 \%)$ \\
Unemployed and not a student & $110(24.1 \%)$ \\
Others & $30(6.6 \%)$ \\
Insurance plan (N=462) & \\
Private & $330(71.4 \%)$ \\
Medicare/Medicaid & $125(27.1 \%)$ \\
Military related & $4(0.9 \%)$ \\
No insurance & $3(0.6 \%)$ \\
\hline
\end{tabular}

*Some participants indicated they had more than 1 insurance type, thus insurance type is not mutually exclusive.

indicated their uterus was going to be removed, 52 (35.9\%) indicated that their cervix was going to be removed, and $11(7.6 \%)$ reported that they were not sure which organs would be involved. Among the 228 participants who reported a plan for total hysterectomy, $208(91.2 \%)$ reported that their uterus was going to be removed, $143(62.7 \%)$ reported that their cervix was going to be removed, and $17(7.5 \%)$ said that they were not sure which organs would be involved in the surgery. A total of 79 participants $(17.3 \%)$ reported that they were not sure what type of surgery was planned. Among these 79 women unsure of the planned procedure type, $63(79.8 \%)$ reported that their uterus was going to be removed and $27(34.2 \%)$ reported that they expected removal of the cervix (Table 2).
After excluding women who reported "not sure" when indicating what surgery type they expected, 377 women remained in the analytical sample. Among those who reported they did not plan to have their cervix removed, only 93 (52\%) women indicated they would be undergoing a partial hysterectomy (removal of the uterus with preservation of the cervix). Among those who expected removal of the cervix during surgery, 52 (26.3\%) women reported they would be having a partial hysterectomy and $146(73.7 \%)$ reported a different planned surgical approach. These results have a kappa coefficient of 0.26 (95\% CI: 0.16-0.36), suggesting a low level of agreement between the expected surgery type and cervix removal (Table 3 ).

Among those who reported planned uterus and cervix removal, $142(72.8 \%)$ women indicated they would be undergoing a total hysterectomy (removal of the uterus and cervix simultaneously). Among those who did not report planned removal of both the uterus and cervix during surgery, $86(47.3 \%)$ women reported the planned surgery as total hysterectomy and $96(52.7 \%)$ reported a different planned surgical approach. These results also had a kappa coefficient of 0.26 (95\% CI: 0.16-0.36), suggesting participant reporting of type of surgery was not accurate for the reported planned organ removal (Table 3 ).

\section{Expected Surgery vs Procedure Performed}

Among the 144 women who reported a planned partial hysterectomy and whose EMR were reviewed, only $15(10.4 \%)$ had a partial hysterectomy as recorded in their EMR. The agreement between participants' reports of planned partial hysterectomy and official surgical reports was quite low, with a kappa coefficient of 0.05 (95\% CI: $-0.07-0.17)$. Among the 148 women who reported that they planned to not have a total hysterectomy, $133(89.9 \%)$ participants did indeed have a total hysterectomy as recorded in their EMR $(\kappa=0.05$; 95\% CI: $-0.07-0.17)$ (Table 3).

\section{Expected Organ Removal vs Procedure Performed}

Among 37 participants with EMR-documented partial hysterectomy, $36(97.3 \%)$ reported in the presurgery survey that their uterus was going to be removed and 13 (35.1\%) reported that their cervix was going to be removed. For those with an EMR- 
Table 2. Summary of Participant Self-Report of Planned Organ Removal and Self-Report of Planned Surgical Approach

\begin{tabular}{lccccc}
\hline & \multicolumn{3}{c}{ Self-Report of Planned Surgical Approach } & \\
\cline { 2 - 5 } $\begin{array}{l}\text { Self-Report of Planned } \\
\text { Organ Removal }\end{array}$ & $\begin{array}{c}\text { Partial } \\
\text { Hysterectomy }\end{array}$ & $\begin{array}{c}\text { Total } \\
\text { Hysterectomy }\end{array}$ & $\begin{array}{c}\text { Radical } \\
\text { Hysterectomy }\end{array}$ & Not Sure & Total \\
\hline \multirow{3}{*}{ Uterus } & $\mathrm{n}=145$ & $\mathrm{n}=228$ & $\mathrm{n}=4$ & $\mathrm{n}=79$ & $\mathrm{~N}=456$ \\
Cervix & $130(89.7 \%)$ & $208(91.2 \%)$ & $3(75.0 \%)$ & $63(79.8 \%)$ & $404(88.6 \%)$ \\
\hline
\end{tabular}

Percentages were calculated from respective column total.

documented total hysterectomy, 366 of 415 (88.2\%) reported that their uterus was going to be removed and only $211(50.8 \%)$ reported that their cervix was going to be removed. Among the 415 participants who underwent total hysterectomy, only 207 participants $(49.9 \%)$ reported that both their uterus and cervix were to be removed. There was little agreement between expected and actual cervix removal $(\kappa=0.05 ; 95 \% \mathrm{CI}$ : $-0.05-0.14)$ or expected and actual cervix and uterus removal ( $\kappa=0.04$; 95\% CI: $-0.05-0.13$ ). The agreement was similarly poor for salpingectomy $(\kappa=0.06 ; 95 \%$ CI: -0.06-0.18). However, although only weak, the agreement was strongest for oophorectomy $(\kappa=0.55$; 95\% CI: 0.47-0.64) (Table 3).

Overall, the kappa values did not vary by insurance status, age, marital status, race, or reason for hysterectomy, with the single exception of women who underwent hysterectomy because of endometriosis (data not shown). Among those having a hysterectomy due to endometriosis, the agreement between whether a woman expected to have her ovaries removed and whether she had them removed was strong $(\kappa=0.82$; 95\% CI: 0.59-1.05).

\section{DISCUSSION}

While hysterectomy has been the most common nonobstetrical surgery in the United States for decades, ${ }^{2,3}$ it is not uncommon for women to inaccurately report the organs/tissues that will be removed during their planned hysterectomy. Prior work regarding this topic involving focus groups conducted by two separate research teams found that a significant number of women lack sufficient knowledge about the details of their hysterectomy and anatomy to accurately report the details of their hysterectomy. ${ }^{8,11}$ Based on the information collected from participants in our study, in addition to the clinical data and surgical details provided by the EMR, the level of agreement between what patients expected and what physicians actually do in the operating room was tested. Most notably, nearly $10 \%$ of women who were planning to have a hysterectomy did not report that their complete or partial uterus would be removed and $36 \%$ of the women who reported a planned partial hysterectomy incorrectly thought that they would also have their cervix removed.

Similar results were reported in a cohort of 190 predominately white and college-educated women who had undergone a minimally invasive hysterectomy - only $67 \%$ were able to report correctly whether they had their cervix removed and whether they needed future cervical cancer screening. ${ }^{12}$ Further, only $57 \%$ of the women understood the purpose of a Pap test. ${ }^{12}$ Other publications also have demonstrated the lack of understanding of the female anatomy. In a study of college students that used a word bank to label a diagram of the female reproductive tract, less than $60 \%$ of the 138 women were able to correctly label the cervix and nearly $60 \%$ were able to identify the uterus. ${ }^{13}$ In a group of 500 patients (age 18-59 years) from an academic obstetrics and gynecology practice in the United States, 29\% reported that hysterectomy included removal of the ovaries and tubes and approximately $25 \%$ of the women thought menstruation would continue after hysterectomy. ${ }^{14}$ The same study found $59 \%$ of the women did not report that removing the entire uterus would eliminate the possibility for cervical cancer, while two-thirds of the 
Table 3. Comparison of Pre- and Postsurgical Data With Respect to Reported Planned Organ Removal, Surgical Approach, and Electronic Medical Record (EMR)

\begin{tabular}{|c|c|c|c|c|}
\hline \multirow[b]{2}{*}{$\begin{array}{l}\text { Self-Report of Planned } \\
\text { Organ Removal }\end{array}$} & \multicolumn{3}{|c|}{ Self-Report of Planned Surgical Approach } & \multirow[b]{2}{*}{ Kappa $(95 \% \mathrm{CI})$} \\
\hline & $\begin{array}{c}\text { Partial } \\
\text { Hysterectomy }\end{array}$ & $\begin{array}{c}\text { Not Partial } \\
\text { Hysterectomy }\end{array}$ & Total $\mathbf{N}^{\mathbf{a}}$ & \\
\hline Not cervix & $93(52 \%)$ & $86(48 \%)$ & 179 & \\
\hline Cervix & $52(26.2 \%)$ & $146(73.7 \%)$ & 198 & $0.26(0.16-0.36)$ \\
\hline \multirow[t]{2}{*}{ Total } & 145 & 232 & 377 & \\
\hline & $\begin{array}{l}\text { Total } \\
\text { Hysterectomy }\end{array}$ & $\begin{array}{l}\text { Not Total } \\
\text { Hysterectomy }\end{array}$ & Total $\mathbf{N}^{\mathrm{a}}$ & Kappa $(95 \% \mathrm{Cl})$ \\
\hline Uterus + cervix & $142(72.8 \%)$ & $53(27.2 \%)$ & 195 & \\
\hline Not [uterus + cervix] & $86(47.3 \%)$ & $96(52.8 \%)$ & 182 & $0.26(0.16-0.36)$ \\
\hline \multirow[t]{2}{*}{ Total } & 228 & 149 & 377 & \\
\hline & \multicolumn{3}{|c|}{ EMR Report of Completed Surgical Approach } & \\
\hline $\begin{array}{l}\text { Self-Report of Planned } \\
\text { Surgical Approach }\end{array}$ & $\begin{array}{c}\text { Partial } \\
\text { Hysterectomy }\end{array}$ & $\begin{array}{c}\text { Not Partial } \\
\text { Hysterectomy }\end{array}$ & Total $\mathbf{N}^{b}$ & Kappa $(95 \%$ Cl) \\
\hline Partial hysterectomy & $15(10.4 \%)$ & $129(89.6 \%)$ & 144 & \\
\hline Not partial hysterectomy & $14(6.0 \%)$ & $218(94 \%)$ & 232 & $0.05(-0.07-0.17)$ \\
\hline \multirow[t]{2}{*}{ Total } & 29 & 347 & 376 & \\
\hline & $\begin{array}{c}\text { Total } \\
\text { Hysterectomy }^{\mathrm{d}}\end{array}$ & $\begin{array}{c}\text { Not Total } \\
\text { Hysterectomy }\end{array}$ & Total $\mathbf{N}^{\mathbf{b}}$ & Kappa $(95 \%$ CI) \\
\hline Total hysterectomy & $214(93.9 \%)$ & $14(6.1 \%)$ & 228 & \\
\hline Not total hysterectomy & $133(89.9 \%)$ & $15(10.1 \%)$ & 148 & $0.05(-0.07-0.17)$ \\
\hline \multirow[t]{2}{*}{ Total } & 347 & 29 & 376 & \\
\hline & \multicolumn{3}{|c|}{ EMR Report of Completed Surgical Approach } & \\
\hline $\begin{array}{l}\text { Self-Report of Planned } \\
\text { Organ Removal }\end{array}$ & $\begin{array}{l}\text { Partial } \\
\text { Hysterectomy }\end{array}$ & $\begin{array}{c}\text { Not Partial } \\
\text { Hysterectomy }\end{array}$ & Total $\mathbf{N}^{\mathrm{c}}$ & Kappa (95\% CI) \\
\hline Not cervix & $24(10.5 \%)$ & $204(89.5 \%)$ & 228 & \\
\hline Cervix & $13(5.8 \%)$ & $211(94.2 \%)$ & 224 & $0.05(-0.05-0.14)$ \\
\hline \multirow[t]{2}{*}{ Total } & 37 & 415 & 452 & \\
\hline & $\begin{array}{l}\text { Total } \\
\text { Hysterectomy }^{\mathrm{d}}\end{array}$ & $\begin{array}{l}\text { Not Total } \\
\text { Hysterectomy }\end{array}$ & Total $\mathbf{N}^{\mathrm{c}}$ & Kappa (95\% Cl) \\
\hline [Uterus + cervix] & $207(94.1 \%)$ & $13(5.9 \%)$ & 220 & \\
\hline Not [uterus + cervix] & $208(89.7 \%)$ & $24(10.3 \%)$ & 232 & $0.04(-0.05-0.13)$ \\
\hline \multirow[t]{2}{*}{ Total } & 415 & 37 & 452 & \\
\hline & Salpingectomy ${ }^{d}$ & $\begin{array}{l}\text { Not } \\
\text { Salpingectomy }\end{array}$ & Total $\mathbf{N}^{\mathrm{c}}$ & Kappa (95\% Cl) \\
\hline Yes & $276(95.2 \%)$ & $14(4.8 \%)$ & 290 & \\
\hline No & $146(90.1 \%)$ & $16(9.9 \%)$ & 162 & $0.06(-0.06-0.18)$ \\
\hline \multirow[t]{2}{*}{ Total } & 422 & 30 & 452 & \\
\hline & Oophorectomyd & $\begin{array}{l}\text { Not } \\
\text { Oophorectomy }\end{array}$ & Total $\mathbf{N}^{\mathrm{c}}$ & Kappa (95\% CI) \\
\hline Yes & $93(74.4 \%)$ & $32(25.6 \%)$ & 125 & \\
\hline No & $53(16.2 \%)$ & $274(83.8 \%)$ & 327 & $0.55(0.47-0.64)$ \\
\hline Total & 146 & 306 & 452 & \\
\hline \multicolumn{5}{|c|}{ aTotal N: 377 (456 patients who had presurgery surveys - 79 self-reporting "not sure"). } \\
\hline \multirow{2}{*}{\multicolumn{5}{|c|}{$\begin{array}{l}{ }^{b} \text { Total N: } 376 \text { (452 women who underwent hysterectomy - } 76 \text { (self-reporting "not sure). } \\
{ }^{c} \text { Total N: } 452 \text { (patients who underwent hysterectomy). }\end{array}$}} \\
\hline & & & & \\
\hline \multicolumn{5}{|c|}{$\begin{array}{l}\text { ¿Partial Hysterectomy = removal of uterus; Total Hysterectomy = removal of uterus }+ \text { cervix; Salpingectomy = removal of } \\
\text { fallopian tubes; Oophorectomy = removal of ovaries. }\end{array}$} \\
\hline \multicolumn{5}{|c|}{ Percentages were calculated from respective row total. } \\
\hline
\end{tabular}


women thought they would need to continue to have Pap tests after a total hysterectomy. ${ }^{14}$ Some of these results are not directly comparable to those reported herein, as the women in our analyses were actually planning to have a hysterectomy and had already completed presurgical counseling.

The findings suggest there should be concern about these women obtaining optimal future care. Surgical details are routinely collected as part of any health history, and care plans are affected by a patient's history. Giving inaccurate details about a health history or incomplete details about prior surgeries could lead to missed screening recommendations or inaccurate diagnoses or health score calculations. Reid et al found that women in the waiting room area at a women's health clinic had significant knowledge deficits regarding female pelvic anatomy and wanted their physicians to provide them with better education and counseling. ${ }^{15}$ Such findings highlight that alreadyexisting systems of patient education are failing to properly educate women.

In a study by Wade et al, in which focus groups were conducted with hysterectomy patients in the 2-year period after their surgery, women expressed concern regarding lack of information and lack of participation in decision-making regarding their hysterectomy. ${ }^{11}$ They reported feeling the quality and quantity of information about the surgery and their own anatomy and physiology was insufficient, specifically stating they wanted to know more about organ functions and which organs remained after surgery. ${ }^{11}$ Women expressed a need to have their physicians spend more time with them and a need to have access to educational media. These issues are not unique to women undergoing hysterectomy.

Almost 20 years after the Wade et $\mathrm{al}^{11}$ publication, Bossick et $\mathrm{al}^{8}$ conducted focus groups with women who had a hysterectomy at Henry Ford Health System. The women expressed similar concerns as those women 18 years prior. Not all women were able to report the type of hysterectomy they had or whether they had their tubes or ovaries removed, findings that spurred our current analysis. Further, our results along with information in the literature suggest that the lack of understanding appears to cross age and race groups.
These results highlight a persistent gap in women's understanding of hysterectomy. The reasons behind this knowledge gap could be due to lack of patient understanding of basic anatomy or challenges in surgical counseling and in-clinic patient education, but is likely a combination of these factors. Indeed, a 2013 study found that health literacy affects many U.S. women and plays an important role in women's health. ${ }^{16}$ In fact, health literacy's impact is not limited to women's health and affects health outcomes of other diseases like diabetes, ${ }^{17}$ inflammatory bowel disease, ${ }^{18}$ and heart failure. ${ }^{19}$ Lower health literacy also has been associated with worse health outcomes and quality of life in patients undergoing day surgery $^{20}$ as well as lower patient satisfaction and higher health care cost. ${ }^{21}$ Although our findings do not isolate the cause of the knowledge deficiency, the analyses do highlight an important opportunity to improve the care experience for women undergoing hysterectomy.

Based on the systematic review from Fredericks et al, and with media resources readily available, educational materials could be prepared and widely disseminated to better educate women about their own anatomy and how it will be affected by hysterectomy. ${ }^{22}$ Surgeons must council patients both before and after surgery to carefully explain any changes during surgery that deviated from the presurgical plan. This change in "routine care" must be led by clinicians who cannot assume anything about how well a patient understands her own anatomy. Indeed, Williams et al have shown that improving patient education on hysterectomy would improve patients' experiences. ${ }^{23}$

Patient input should be sought for intervention development. For example, in a randomized control trial, women who were planning to undergo hysterectomy were randomized to usual care $(n=52)$ or a scripted video $(n=57)$ for their presurgical counseling. ${ }^{24}$ The script for the video was created by the investigators and does not appear to have contained patient input. The participants were then asked true/false and multiple-choice questions about key information including knowledge about anatomy and the hysterectomy procedure. Those who were in the video arm had better knowledge scores initially, but not at 6 weeks after surgery. ${ }^{24}$ 


\section{Limitations}

As with any epidemiological study, there are limitations to this work. The participant-reported information was collected within 2 weeks prior to hysterectomy and after presurgical counseling. During this time, surgical plans for some participants might have changed and this could have been communicated to the patient by their physician and could explain some, but likely not all, of the differences between planned hysterectomy type and the type that was performed. If the surgery had been explained to the woman in layman's terms, such as use of the word "womb" instead of uterus, we would not have captured this difference.

\section{CONCLUSIONS}

In summary, this work demonstrates the need to improve patient understanding of their clinical care and its implications. Hysterectomy is one of the most common surgeries for women, yet many women fail to understand how their body will change after this major surgery. A great opportunity exists to improve health literacy and educate women about their own basic anatomy, with a greater goal of improving their health and care satisfaction.

\section{Patient-Friendly Recap}

- Hysterectomy is a very common surgery and there are different types of hysterectomies that involve removal of different organs.

- The authors asked women undergoing hysterectomy to report the type of hysterectomy procedure planned and which organs would be removed. Surgical data from participants' electronic medical records also was collected.

- Many women were not able to accurately report the changes to their anatomy from the planned procedure.

- This work highlights the need to improve patient understanding of their clinical care, basic anatomy, and how both may change following surgery.

\section{Author Contributions}

Study design: Sangha, Wegienka. Data acquisition or analysis: all authors. Manuscript drafting: all authors. Critical revision: Kassem, Sangha, Wegienka.

\section{Conflicts of Interest}

None.

\section{Funding Sources}

This research was funded by the Agency for Healthcare Research and Quality (grant no. 5R24HS022417-05).

\section{References}

1. Sutton C. Hysterectomy: a historical perspective. Baillieres Clin Obstet Gynaecol. 1997;11:1-22. CrossRef

2. Torpy JM, Lynm C, Glass RM. JAMA patient page. Hysterectomy. JAMA. 2004;291:1526. CrossRef

3. Wilcox LS, Koonin LM, Pokras R, Strauss LT, Xia Z, Peterson HB. Hysterectomy in the United States, 1988-1990. Obstet Gynecol. 1994;83:549-55. CrossRef

4. Merrill RM. Hysterectomy surveillance in the United States, 1997 through 2005. Med Sci Monit. 2008;14(1):CR24-31.

5. Kuppermann M, Summitt RL Jr, Varner RE, et al. Sexual functioning after total compared with supracervical hysterectomy: a randomized trial. Obstet Gynecol. 2005;105:1309-18. CrossRef

6. Kuppermann M, Learman LA, Schembri M, et al. Predictors of hysterectomy use and satisfaction. Obstet Gynecol. 2010;115:543-51. CrossRef

7. Greer WJ, Richter HE, Wheeler TL, et al. Long-term outcomes of the Total or Supracervical Hysterectomy (TOSH) trial. Female Pelvic Med Reconstr Surg. 2010;16:49-57. CrossRef

8. Bossick AS, Sangha R, Olden H, Alexander GL, Wegienka G. Identifying what matters to hysterectomy patients: postsurgery perceptions, beliefs, and experiences. J Patient Cent Res Rev. 2018;5:167-75. CrossRef

9. McHugh ML. Interrater reliability: the kappa statistic. Biochem Med (Zagreb). 2012;22:276-82. CrossRef

10. Viera AJ, Garrett JM. Understanding interobserver agreement: the kappa statistic. Fam Med. 2005;37:360-3.

11. Wade J, Pletsch PK, Morgan SW, Menting SA. Hysterectomy: what do women need and want to know? J Obstet Gynecol Neonatal Nurs. 2000;29:33-42. CrossRef

12. Mattingly M, Juran R, Su I, Ebinger J, Daggy J, Tucker Edmonds B. Patient knowledge of hysterectomy and pap screening after minimally invasive hysterectomy. Patient Educ Couns. 2017;100:121-5. CrossRef

13. Volck W, Ventress ZA, Herbenick D, Hillard PJ, Huppert JS. Gynecologic knowledge is low in college men and women. J Pediatr Adolesc Gynecol. 2013;26:161-6. CrossRef

14. Harmanli O, Ilarslan I, Kirupananthan S, Knee A, Harmanli A. Women's perceptions about female reproductive system: a survey from an academic obstetrics and gynecology practice. Arch Gynecol Obstet. 2014;289:1219-23. CrossRef

15. Reid JA, Templeman CL, Groneberg DA, Brueggmann D, Jaque JM. Patients' knowledge of female pelvic health and related educational preferences. J Community Health. 2017;42:147-54. CrossRef

16. Corrarino JE. Health literacy and women's health: challenges and opportunities. J Midwifery Womens Health. 2013;58: 257-64. CrossRef

17. Saeed H, Saleem Z, Naeem R, Shahzadi I, Islam M. Impact of health literacy on diabetes outcomes: a cross-sectional study from Lahore, Pakistan. Public Health. 2018;156:8-14. CrossRef 
18. Tormey LK, Reich J, Chen YS, et al. Limited health literacy is associated with worse patient-reported outcomes in inflammatory bowel disease. Inflamm Bowel Dis. 2019;25:204-12. CrossRef

19. Matsuoka S, Tsuchihashi-Makaya M, Kayane T, et al. Health literacy is independently associated with self-care behavior in patients with heart failure. Patient Educ Couns. 2016;99:1026-32. CrossRef

20. Hälleberg Nyman M, Nilsson U, Dahlberg K, Jaensson M. Association between functional health literacy and postoperative recovery, health care contacts, and healthrelated quality of life among patients undergoing day surgery: secondary analysis of a randomized clinical trial. JAMA Surg. 2018;153:738-45. CrossRef

21. MacLeod S, Musich S, Gulyas S, et al. The impact of inadequate health literacy on patient satisfaction, healthcare utilization, and expenditures among older adults. Geriatr Nurs. 2017;38:334-41. CrossRef
22. Fredericks S, Guruge S, Sidani S, Wan T. Postoperative patient education: a systematic review. Clin Nurs Res. 2010;19:144-64. CrossRef

23. Williams RD, Clark AJ. A qualitative study of women's hysterectomy experience. J Womens Health Gend Based Med. 2000;9 Suppl 2:S15-25. CrossRef

24. Pallett AC, Nguyen BT, Klein NM, Phippen N, Miller CR, Barnett JC. A randomized controlled trial to determine whether a video presentation improves informed consent for hysterectomy. Am J Obstet Gynecol. 2018;219:277.e1-e7. CrossRef

(C) 2019 Aurora Health Care, Inc. 